\title{
SANIDAD DE PUERTOS, FRONTERAS Y TRANSPORTES
}

La necesidad de defenderse contra las grandes pestilencias que desde sus focos originarios han invadido periódicamente al mundo civilizado, causando en ocasiones verdaderas catástrofes, ocasionando millones de víctimas y sembrando el terror y la devastación desde los tiempos más remotos hasta que los progresos científicos nos han hecho conocer su etiología y medios de transmisión y, como consecuencia, los modos de combatirlas, obligó a las naciones a organizar barreras defensivas, al principio aisladamente y a partir del siglo XIX con un plan de colaboración y coordinación que dió origen a la llamada Higiene Internacional, cuyos resultados, unidos al perfeccionamiento de los medios profilácticos, puede decirse que ha librado a la Humanidad de los terrores que tantas veces padeció y que en ocasiones hizo temer incluso su desaparición, en medio de cuadros aterradores que nos han legado la Literatura y el Arte contemporáneos, obsesionados por las escenas que se desarrollaban.

De estos azotes, el más antiguo y terrible, el más mortífero de los que han asolado al mundo, es la Peste. Sin contar epidemias de los tiempos más remotos, de las que han llegado hasta nosotros noticias y descripciones, como las de la llamada "Peste de Atenas", descrita por Tucídides; la de Antonino y la de Cartago (año 255 a 265), maravillosamente descrita por San Cipriano, epidemias cuya verdadera clasificación es dudosa y que algunos autores conceptúan como de una enfermedad desaparecida del mundo sin relación con la Peste de nuestros días, tenemos la llamada "Peste de Justiniano" en el sigio VI; ésta perfectamente clasificada como tal, descrita por Procopio y que hizo en cincuenta y dos años cien millones de víctimas, y la terrible epidemia del siglo XIV, conocida con diversidad de nombres, como Peste negra, muerte negra, muerte densa, etc.

512 Partiendo del N. de China, la antigua Cathay, y marchando de 
Este a Oeste, atacó sucesivamente India, Persia, Rusia, Alemania y el resto de Europa, llegando a Inglaterra y Noruega e invadiendo todo el mundo conocido entonces. Las descripciones que nos han llegado son verdaderamente pavorosas, impresionando de tal modo a los espíritus en una época de ignorancia y superstición, que dió lugar a las más crueles escenas. Los cálculos de los estragos causados se estiman por unos en un tercio y por otros en la mitad de la población de la Tierra. Las grandes ciudades de Italia quedaron casi despobladas, y así, según Boccacio, Florencia perdió, de abril a julio de 1348, 100.000 habitantes; Génova, 40.000; Nápoles, 60.000, y Venecia, 70.000. En esta ciudad, 80 familias patricias se extinguieron de golpe. Unióse a los terribles estragos de la enfermedad los del hambre, y se hacinaban los cadáveres en las calles de las ciudades, a pesar de abrirse grandes fosas en las que se arrojaban a montones y entre ellos infinidad de personas vivas. Ácusados los judíos de haber envenenado las aguas; eran quemados a millares, hasta el punto de que el Papa Clemente VI redactó un Breve declarándolos inocentes y condenando la persecución de que eran objeto. La violencia de esta espantosa epidemia, la mayor y más mortífera de las que se tienen noticias, duró dos años, pero la enfermedad, atenuada y endémica, siguió en Europa hasta el siglo XVI, y dió lugar a las primeras medidas de reglamentación de cuarentenas y de intentos tan brutales como inútiles de preservación de unas localidades contra otras.

Después de esta plaga, verdaderamente apocalíptica, pareció extinguirse la enfermedad en Europa y pasan muchos años sin dar señales de existencia. En el siglo XVII hace diversas apariciones $\mathbf{y}$. en 1665 la padece Londres, perdiendo 70.000 habitantes. En el siglo XVIII se presentan varias epidemias: Marsella, 1720; Mesina, 1743; Moscou, 1770, y a fines de este siglo y comienzos del XIX hace estragos en Oriente; en Egipto existe un foco permanente que provoca, de 1783 a 1844, 21 epidemias, siendo la más señalada históricamente la de 1799, en la que murieron 2.000 soldados del Ejército de Napoleón. Esta persistencia en Egipto hizo creer erróneamente que este país era el foco originario de la enfermedad. Después de 1844 desaparece del Mediterráno y dé Egipto y se va olvidando, aunque en Mesopotamia y otros puntos de Asia se describe la presentación periódica de una enfermedad que, por el cuadro clínico, es, indudablemente la Peste, con pequeñas incursiones en Cirenaica y en Arabia, que no llegaron a causar alarma hasta 1878, en que la epidemia de Wetlianka amenaza por vía terrestre a Rusia. Sin embar- 513 
go, para su nueva penetración en Europa utiliza la vía marítima. Partiendo del foco endémico de Yunnam, en 1894, invade Cantón, en donde mueren 1.000 personas por semana y forma un gran foco secundario; a partir de este momento se difunde de nuevo por vía marítima por todo el mundo, provocando epidemias en todos los continentes. En Europa, Oporto padece una muy grave, y son muchos los puertos afectados con más o menos mortalidad. En muchas localidades se logra localizarla en los Lazaretos merced a la Sanidad de puertos o marítima, viéndose epidemias sofocadas a bordo de los navios, sin que pasen a tierra. Actualmente, aparte de su foco primitivo asiático, en donde se mantiene el virus permanentemente, existen otros secundarios repartidos por el mundo, constituyendo siempre una amenaza, sofocada y sujeta gracias al conocimiento de los medios de transmisión y de las medidas para detenerlas evitando su entrada, combatirlas eficazmente donde logra atravesar la barrera defensiva, impidiendo además su exportación, a pesar de lo cual en nuestros días ha habido numerosas invasiones y focos de difícil extinción que constantemente provocan nuevas, epidemias, como las que en estos últimos treinta años padecimos en Barcelona, Canarias, Málaga, Melilla y Ceuta, y la que actualmente existe en el Marruecos francés, que es un grave peligro de nuevas invasiones para España.

Si la Peste bubónica es el azote de la Humanidad, principalmente en la Edad Media, en la Edad moderna aparecen en Europa dos nuevas pestilencias, hasta entonces acantonadas en sus países de origen, de los cuales uno estaba todavía oculto tras el "Mar tenebroso", en tierras desconocidas por los hombres hasta que las naves de Castilla arribaron a sus costas. Las costas calientes del Golfo de Méjico guardaban una nueva plaga, la Fiebre amarilla, que bien pronto había de extenderse, principalmente por América, crear focos secundarios en Africa y amenazar a la Península Ibérica; dando lugar a mortíferas epidemias, preferentemente en Andalucía, y creando un serio peligro, tanto mayor cuanto que la creciente rapidez de las comunicaciones hacía cada vez más fácil el transporte del mosquito infectado o del hombre en período de incubación capaz de infectar al mosquito dei género "stegomya", eñ las zonas en que éste vịe. Las condiciones de vida de este insecto hacen que desaparezca más allá de cierta latitud (paralelo 43) y que en Europa, sólo nuestra Península y el sur de Italia sean propias para el desarrollo de la enfer514 medad; la historia epidemiológica nos enseña cómo los casos pre- 
sentados en otros países a bordo de navíos se extinguieron rápidamente, en tanto que en España apareció por vez primera en Cádiz en 1701 y durante un siglo causó más de 300.000 defunciones en la Península Ibérica. De Cádiz pasó a toda Andalucía, y por último, exceptuando la estrecha faja cantábrica, a toda España, incluyendo Baleares. En Barcelona causó en 1821 más de 20.000 víctimas, atacando a unas 80.000 personas. Estas epidemias alarmaron a los demás países europeos; que tomaron grandes medidas contra las procedencias de países infectados, medidas cuya inutilidad sólo el po: terior conocimiente del modo de propagación habia de demostrar. Pero si en longitud tiene un área bien circunscrita, en latitud tiende a propagarse, y nuevos focos, como los del $O$. africano, constituyen siempre una amenaza para países como el nuestro aptos para su invasión y desarrollo. Esto nos obliga a no olvidar nunca este peligro en nuestros puertos, y en un mañana muy próximo, en que la navegación aérea, cuyo desarrollo después de la actual conflagración se adivina tan pujante, nos ponga en contacto rapidísimo con zonas en que es endémica esta plaga-habrá que extremar las medidas en aeródromos y aeropuertos, si queremos evitar brotes epidémicos ya olvidados, cuya extinción, aún conociendo perfectamente los medios de atacarlos, constituiría un grave y oneroso problemे.

La tercera de las llamadas pestilencias exóticas, el Cólera asio tico, a pesar de existir en la India desde los tiempos más remotos, no hizo su aparición en Europa hasta el siglo XIX. Ya en 1817, saliendo del valle superior del Ganges y de Brahmaputra, hizo en la India más de tres millones de víctimas, y saliendo en dos direcciones por vía marítima, por Calcuta y Bombay, se extendió a toda Asia, gran parte de Oceanía, costa oriental de Africa y se detuvo sin penetrar en Europa. Pero en 1827, un nuevo éxodo le hace invadir Europa por el E. y por el S. y causa enormes estragos, propagándose a América del Norte. Durante todo el siglo XIX, sucesivas mortíferas epidemias azotan a Europa, causando millones de víctimas y reproduciendo a veces, salvo circunstancias de tiempo y costumbres, algunos de los cuadros medievales en las epidemias de Peste. En España, de febrero a diciembre de 1886 causa 119.600 defunciones, con 338.685 atacados. Europa entera intenta defenderse con medidas draconianas, sin lograr evitar sucesivas invasiones, hasta que el conocimiento del agente productor y los medios de transmisión van haciendo cada vez más eficaz la defensa, a pesar de lo cual, y ya en nuestra época, ha habido varias epidemias, especialmente en Rusia, y en España focos como los de Cataluña. en 1910. 
Naturalmente estas pestilencias, viniendo de fuera, han penetrado en los países por medio de los transportes, y habiendo preferido frecuentemente la vía marítima, los sitios de entrada han sido ordinariamente los puertos. Al principio, las ciudades con puertos importantes organizaron su propia defensa, y así Venecia, con activo comercio con Levante, creó una oficina de Sanidad y un Lazareto, en el que hacían cuarentena los buques. Génova y Marsella, y paulatinamente todas las grandes ciudades marítimas, organizaron su mecanismo defensivo; pero de una parte la diversidad de criterio entre ellas, y de otra que los navíos, viendo cerrados los grandes puertos cuando venían infectados y la aplicación de severísimas medidas simplemente cuando su procedencia era sospechosa, descargaban en otros pequeños puertos vecinos, y por tanto el peligro para la nación subsistía, fué preciso adoptar medidas en todo el litoral, naciendo la profilaxis nacional. De aquí que esta preocupación diera origen en todos los países a la Sanidad marítima o de puertos, la primera organizada y de antiquísima tradición, pues que remonta a los Lazaretos de Venecia de 1348. Cada nación la organizó con arreglo a su criterio, y en tanto que unas, más preocupadas por los intereses del comercio, reglamentaban con un criterio amplio, otras, más temerosas, por más castigadas o más expuestas, imponían medidas que dificultaban grandemente el comercio y la navegación, con protestas y reclamaciones de los países marineros. La navegación a vapor, al mismo tiempo que por su rapidez aumentaba los peligros, por su mismo ritmo acelerado cada vez se avenía menos a las largas cuarentenas que inmovilizaban a los buques en los Lazaretos, a veces durante meses, y por otra parte, la seguridad de que las medidas no darían resultado de no aplicarse de modo coordinado, hizo que Francia, en 1851, convocara a una conferencia internacional que se reunió en París, y que, si no dió grandes resultados por no ser seguida de convenio, abrió la era de la colaboración entre los países, base hoy de toda la defensa del mundo civilizado. Seis conferencias se sucedieron sin resultados apreciables (París, 1851, 1859; Constantinopla, 1866; Viena, 1874; Washington, 1881, y Roma, 1885) con objeto de unificar medidas, hasta que la conferencia de Viena de 1892 tiene como resultado un Convenio y marca el principio de la verdadera Sanidad Internacional, estableciendo una barrera en Suez para preservar a Europa del Cólera. Tras ésta se sucedieron las reuniones seguidas de Convenio, y así siguieron los de Dresde de 1893, que marca la obligación de un país contaminado de Cólera con res516 pecto a los demás y los derechos de éstos; París, 1894, que se ocupa 
de las profilaxis de las peregrinaciones a la Meca y la barrera del Golfo Pérsico contra el Cólera; Venecia, 1874, que trata de la Peste, olvidada en las anteriores, $y$ extiende a esta pestilencia las medidas acordadas para el Cólera; París, 1903, que amplía las anteriores, fija la duración de la observación y vigilancia de acuerdo con el período de incubación de las enfermedades; Río Janeiro, 1904, y Washington, 1905, inspiradas en las anteriores, suavizan para América las medidas contra la Peste y el Cólera, y en cambio aumentan el rigor para la Fiebre amarilla; París, 1912 y 1926, que perfeccionan las medidas con arreglo a los últimos conocimientos epidemiológicos, y La Haya, de 1933, ésta última de aplicación a la navegación área.

En ellas se estudiaron todos los problemas científicos relacionados con las epidemias, se organizó la barrera común de Europa contra los focos originarios y los peligros de las peregrinaciones para la difusión del Cólera y la Peste, se acordó la notificación de los primeros casos, se creó la Oficina Internacional de Higiene Pública, y como al propio tiempo se sucedían rápidamente los descubrimientos sobre los modos de transmisión de las llamadas pestilencias, se organizaba la defensa con un plan racional, haciendo cada vez más suaves las medidas a adoptar con las procedencias, si bien se obligaba a los países signatarios a un mínimum de instalaciones y servicios y a una uniforme aplicación de medidas, extendiéndolas al Tifus exantemático y a la Viruela.

La creciente rapidez de los transportes y las grandes vías férreas internacionales que hoy ponen en comunicación a los más lejanos países, obligó a organizar las fronteras, que antes se defendían o creían defenderse por el sistema de acordonamiento y cierre de las mismas, como los progresos de la aviación y su utilización comercial obligan a ampliar las medidas de los aeropuertos. La antigua Sanidad marítima pasa a ser Sanidad Exterior con la creación en todos los países de servicios especializados, extendiendo cada vez más su misión con la de impedir la exportación e importación de todas las

- enfermedades infecciosas comunes, la aplicación de la higiene en general a todos los servicios marítimos y de transportes, vacunas preventivas, etc., etc.

España, castigada desde los más remotos tiempos por las epidemias europeas y después por éstas y las de Fiebre amarilla, ponía 517 
en juego su sistema defensivo en puertos y fronteras, siempre con arreglo a las ideas de la época. Pero la primera reglamentación parte de 1855, en que se promulga la Ley de Sanidad, que con el nombre de Sanidad Marítima organiza ésta en todos los puertos con personal especialmente afecto a este servicio, tañto técnico como auxiliar, clasifica los Lazaretos en sucios y de observación, ordena el trato sanitario y las prácticas de las cuarentenas, expurgos, etc., e impone à los barcos con más de sesenta pasajeros la obligación de llevar médico y material sanitario, origen del Cuerpo Médico de la Marina Civil, y es, en suma, la primera organización legal de Sa nidad Exterior, aprovechando las enseñanzas de la fracasada conferencia de París de 1851. En 1887 aparece el primer Reglamento Orgánico de Sanidad Exterior, que organiza administrativamente el personal de esta rama y recoge las conclusiones de la conferencia de Roma de 1885. Desde este momento, en ejecución de los Convenios internacionales que se suceden, todos firmados por España, Sanidad Exterior se perfecciona y desarrolla. Siendo su función el cumplimiento y aplicación de los Acuerdos, cada paso que da la Higiene Internacional se refleja en nuestra legislación y organización; así los primeros Convenios (Venecia, 1882; Dresde, 1893; París, 1894, y Venecia, 1897) se traducen en el Reglamento de 1899. Este, que consta de tres grandes títulos, ya da como misión dé Cuerpo de Sanidad Exterior impedir la importación de todas las enfermedades infecciosas, a más de las pestilenciales y de las epizootias, la vigilancia de la higiene de puertos y buques, organiza la sanidad de fronteras, crea, a las inmediatas órdenes del Director general un Jefe de Sanidad Exterior, el más alto funcionario técnico de la Dirección General; clasifica las Estaciones Sanitarias por categorías, marcando el personal y material que deben tener, dispone que funcionen cinco Lazaretos que permitan el aislamiento de buques, toda clase de operaciones de desinfección y la hospitalización de enfermos; marca las atribuciones de los Directores de Sanidad; organiza el Cuerpo Médico de la Marina Civil, reglamentando el ingreso y sus funciones; dicta medidas para la higiene marítima en puertos y buques, agua de bebida, víveres, material sanitario de los barcos y a la salida de los mismos para impedir la exportación de €nfermedades, y es, en suma, código completísimo, de acuerdo con las más adelantadas ideas. A la conferencia de París de 1903 sucede el Reglamento de 1909, y a la de 1912, el de 1917; éste, modificado en 1920, dedica dos extensos capítulos a los servicios sanitarios de Fe518 rrocarriles, ocupándose de los transportes terrestres, de acuerdo con 
la Instrucción General de Sanidad, que encomienda a Sanidad Exterior la vigilancia sanitaria de las comunicaciones y legisla sobre la higiene, tanto del material móvil cuanto de las estaciones.

Al tiempo que se legisla, cumpliendo fielmente los Acuerdos internacionales, tanto por Reglamentos orgánicos cuanto por Decretos y Ordenes ministeriales, los brotes de Peste y Cólera, algunos de los cuales prenden en nuestro país, hacen que nuestra organización defensiva alcance un grado máximo de perfeccionamiento, modernizando los dos Lazaretos, únicos a que nos obligan los Convenios; dotando a los puertos de personal seleccionado y material modernísimo que colocan a Sanidad Exterior (Puertos y Fronteras) a la cabeza de la de los países más adelantados; se amplían sus funciones a la vigilancia de importación de sustancias alimenticias; se multiplican los laboratorios y se hacen estudios y ensayos de procedimientos, perfeccionando los de otras naciones, que después son adoptados y motivan algunas visitas a nuestros puertos de sanitarios extranjeros, que han de aplicar a los suyos las enseñanzas derivadas de los mismos, principalmente en desratización y desinsectación. Por mucho años constituye Sanidad Exterior la avanzada sanitaria de nuestro país y su personal es encargado de combatir y sofocar los focos de Cólera en Cataluña y los de Peste en Barcelona, Canarias, Málaga y Norte de Marruecos, pues si Sanidad Interior contaba con un código tan perfecto como la Instrucción general de Sanidad, aún no había evolucionado ni en personal ni en organización, como había de hacerlo muy pronto, hasta alcanzar el perfeccionamiento de los. últimos años. La creciente importancia de la higiene de los transportes hizo que en 1925 se redactara un Reglamento de Vías Férreas, ampliado por varias disposiciones a los demás medios de comunicación, incluyendo tranvías, metro, autobuses, etc.

Los últimos Convenios sanitarios de París de 1926 y La Haya de 1933 dan lugar al Reglamento de 1934, hoy vigente, que es en sustancia copia dèl primero y amplía a la navegación aérea la jurisdicción de Sanidad Exterior en cumplimiento del segundo.

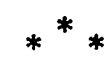

Pero al mismo tiempo que España seguía al día el progreso sanitario en lo referente a higiene internacional y profilaxis nacional, por medio del Cuerpo de Sanidad Exterior, la Sanidad Interior, que había quedado rezagada en las postrimerías del siglo último y principios del actual, fué desarrollándose a partir de la Instrucción de 519 
1904, que creaba las Inspecciones provinciales, al principio lentamente y con rápida y creciente perfección a partir de 1921, con la creación de las Brigadas Sanitarias, embrión de los Institutos Provinciales de Higiene que se organizan en cumplimiento del Estatuto de 1925. Esta es hoy el arma más eficaz con que cuenta la Sanidad Nacional en su organización provincial, y la conveniencia de robustecerla cada vez más, de evitar duplicidad de servicios, de coordinar y simplificar la misión sanitaria utilizando todos los recursos de que en cada localidad pueden disponerse (laboratorios, dispensarios, hospitales de aislamiento, con todas las armas con que cuentan las distintas Luchas, etc.) aconsejaba la unificación de los servicios de las tres ramas sanitarias, como ya se había unificado el personal técnico desde 1929 con el nombre de Cuerpo Médico de Sanidad Nacional. Esta fusión de servicios, cuya conveniencia fué reconocida en el primer Congreso de Sanidad Nacional, se llevó a cabo en 1939, pasando Sanidad Exterior a ser en lo provincial un servicio unido a la Jefatura, y en las poblaciones no capitales de provincia funcionando además como Centro secundario de Higiene Rural. La antigua Inspección General de Sanidad Exterior pasó a denominarse de Desinfecciones, Puertos, Fronteras y Transportes, que actualmente funciona en la Dirección General, coordinada con los demás servicios sanitarios.

Eugenio Pastor Krauel

Inspector General de Puertos y Fronteras 